(2) Open Access Full Text Article

\title{
Increased biogenic catecholamine and metabolite levels in two patients with malignant catatonia
}

\author{
This article was published in the following Dove Press journal: \\ Neuropsychiatric Disease and Treatment \\ 12 August 2013 \\ Number of times this article has been viewed
}

\section{Koichi Nisijima \\ Department of Psychiatry, Jichi Medical University, Tochigi, Japan}

Correspondence: Koichi Nisijima Department of Psychiatry, Yakushiji Shimotuke-Shi Tochigi-Ken, 329-0498, Japan

$\mathrm{Tel}+8 \mathrm{I} 285587364$

Fax+8I285446198

Email midorin@jichi.ac.jp
Abstract: The pathophysiology of malignant catatonia, a rare life-threatening psychiatric syndrome, has not yet been elucidated. This paper reports on two patients with malignant catatonia who showed elevated urinary or plasma catecholamine levels. Patient 1 had high catecholamine and metabolite levels in a 24-hour urine sample, and patient 2 had elevated plasma catecholamine levels. These findings indicate the presence of peripheral sympathetic nervous system hyperactivity in malignant catatonia. Symptoms of autonomic dysfunction, including tachycardia, labile blood pressure, and diaphoresis, are typical features of malignant catatonia and may be related to the increased levels of biogenic amines in these cases. Although the findings in the present study cannot entirely explain the pathophysiology of malignant catatonia, they do indicate that hyperactivity of the sympathetic nervous system may be involved in the pathology of this condition.

Keywords: malignant catatonia, catecholamine levels, neuroleptic malignant syndrome

\section{Introduction}

Malignant catatonia is a rare, life-threatening psychiatric syndrome characterized by stupor, excitement, negativism, fever, tachycardia, increased muscle tone, and symptoms of autonomic instability, such as labile blood pressure and diaphoresis. In 1934, Stauder first described the disease as "lethal catatonia" because the mortality rate of malignant catatonia at that time was reportedly almost $100 \% .^{1}$ In recent years, the mortality rate has been decreasing thanks to early recognition, careful monitoring for complications, and the introduction of appropriate therapy, such as fluid replacement and electroconvulsive therapy; consequently, the disease is now referred to as malignant catatonia rather than lethal catatonia. ${ }^{1,2}$

In the Diagnostic and Statistical Manual of Mental Disorders, Fourth Edition, published by the American Psychiatric Association, catatonia is included only as a subtype of schizophrenia. However, since there are many psychiatric disorders which include catatonic symptoms, catatonia is divided into several forms, of which malignant catatonia is considered to be the most severe. ${ }^{3}$ Specifically, malignant catatonia is characterized by the presence of simple catatonia combined with hyperthermia and autonomic instability.

Neuroleptic malignant syndrome is another life-threatening psychiatric syndrome. Malignant catatonia and neuroleptic malignant syndrome have similar clinical symptoms, and some investigators have recently suggested a common neurochemical basis for the two conditions. ${ }^{4,5}$

Several therapeutic studies on malignant catatonia have been reported, but few, if any, the pathophysiology of malignant catatonia remain unknown. This paper reports on 
the urinary and plasma catecholamine and metabolite levels in two patients with malignant catatonia. These results will help to elucidate the pathophysiology of this rare but lifethreatening condition.

\section{Case reports Case I}

The patient was an 18-year-old man with bipolar disorder. At age 14 years, he began to exhibit repeated episodes of mania followed by depression in approximately one-month cycles. His mental state was stabilized with lithium carbonate (dose $1,300 \mathrm{mg} /$ day, blood concentration $0.74 \mathrm{mEq} / \mathrm{L}$ ). After remaining mentally stable for 2 years, the dosage was tapered and finally discontinued. Three months after discontinuing lithium therapy, he experienced a depressive state lasting approximately 10 days. Lithium carbonate $600 \mathrm{mg}$ /day was restarted, but the depressive state persisted throughout June and July. In August, the dosage was increased to $800 \mathrm{mg} /$ day, but when the depressive state recurred, he was admitted to our hospital on August 12. His psychiatric condition shifted to a hypomanic state the next day, but subsided on August 30. On September 9, he suddenly became stuporous, and his temperature increased to $37.8^{\circ} \mathrm{C}$. Because he was unable to eat or drink independently, he received intravenous fluid replacement, and the course of his condition was observed without administering any drugs. Blood analysis revealed a slight increase in the level of serum creatine kinase to $88 \mathrm{IU} / \mathrm{L}$ (normal range 13-70 IU/L), and an increased white blood cell count $\left(14,000 / \mathrm{mm}^{3}\right)$. On September 10 , the patient's body temperature was $37.8^{\circ} \mathrm{C}$, and rose to $38^{\circ} \mathrm{C}$ on September 11-13. An antipyretic (indomethacin $50 \mathrm{mg}$ ) was administered intrarectally on two occasions, but did not appear to reduce the patient's fever. An antibiotic was administered intravenously. Because his C-reactive protein level $(0.006 \mathrm{mg} / \mathrm{dL})$ on September $13 \mathrm{did}$ not indicate infection, administration of the antibiotic was discontinued. He had severe diaphoresis and urinary incontinence, and his entire body trembled sporadically. At the same time, his systolic blood pressure increased to $180-190 \mathrm{mmHg}$, and his pulse rate was $100-120$ beats per minute. Antihypertensive drugs such as alpha or beta blockers were not administered. On September 16, he had a fever of $38.4^{\circ} \mathrm{C}$. He exhibited increased muscle tone but no muscle rigidity. On September 18, no abnormal findings were found on lumbar puncture or on abdominal computed tomography and echography. His fever persisted in the range of $37.0^{\circ} \mathrm{C}-37.8^{\circ} \mathrm{C}$ until October 4 . His stupor improved spontaneously thereafter.
On September 29, a 24-hour urine sample revealed high levels of adrenaline (91.1 $\mu \mathrm{g} /$ day; normal range $3-15 \mu \mathrm{g} /$ day), noradrenaline $(168.7 \mu \mathrm{g} /$ day; normal range $26-121 \mu \mathrm{g} /$ day), and vanillylmandelic acid (6.5 mg/day; normal range 1.4-5.1 mg/day). On October 11, he appeared to have recovered, and levels of adrenaline (10.7 $\mu \mathrm{g}$ /day), noradrenaline (46.7 $\mu \mathrm{g} /$ day), and vanillylmandelic acid (3.1 $\mathrm{mg} / \mathrm{day})$ returned to within normal range.

\section{Case 2}

A 44-year-old man who had been diagnosed with schizophrenia at 23 years of age was admitted with symptoms of psychomotor agitation, auditory hallucinations, and emotional instability. He was prescribed chlorpromazine $150 \mathrm{mg} /$ day, haloperidol $9 \mathrm{mg} /$ day, biperiden $6 \mathrm{mg} /$ day, carbamazepine $600 \mathrm{mg} /$ day, and lithium carbonate $600 \mathrm{mg} /$ day. A few months later, his psychiatric symptoms had improved, and his mood had become stable. However, on February 1, his psychiatric symptoms suddenly worsened. He developed restlessness, excitation, and paranoid thoughts. An increased dose of antipsychotics and frequent intramuscular injections of chlorpromazine and haloperidol did not improve his psychotic symptoms. He exhibited recurring episodes of stupor and excitement. On February 15, his body temperature increased to $39.5^{\circ} \mathrm{C}$, his systolic blood pressure increased to $170 \mathrm{mmHg}$, his pulse rate was 120 beats per minute, and he exhibited diaphoresis. Blood analysis on February 17 revealed a serum creatine kinase level of 10,110 IU/L (normal range 46-210 IU/L) and a white blood cell count of $8,100 / \mathrm{mm}^{3}$. All antipsychotics were stopped, and fluid replacement and dantrolene $40 \mathrm{mg}$ /day were started. On February 18, he was transferred to our hospital. On admission, a cerebrospinal fluid examination revealed no abnormal findings. His body temperature was $39.4^{\circ} \mathrm{C}$, and he had labile blood pressure (systolic blood pressure 130-170 $\mathrm{mmHg}$ ). He exhibited marked diaphoresis but no muscle rigidity. His serum creatine kinase value was 2,744 IU/L and his white blood cell count was $9,600 / \mathrm{mm}^{3}$. The patient received intravenous fluids and administration of dantrolene was continued.

From the night of February 18, the patient showed intermittent excitement; however, repeated injections of intravenous diazepam $10 \mathrm{mg}$ were ineffective. Therefore, electroconvulsive therapy was started on February 23. On March 3, after completion of five electroconvulsive therapy sessions, his psychiatric and physical symptoms resolved.

His catecholamine levels were not determined in 24-hour urine samples because his high level of excitement made this impractical. However, plasma catecholamine levels 
were measured on the morning of February 18 when he was transferred to our hospital. This measurement revealed high levels of adrenaline $(102.0 \mathrm{pg} / \mathrm{mL}$; normal morning range $<100.0 \mathrm{pg} / \mathrm{mL})$, noradrenaline $(1,672.0 \mathrm{pg} / \mathrm{mL}$; normal morning range $100-450 \mathrm{pg} / \mathrm{mL}$ ), and dopamine (128.0 pg/mL; normal morning range $<20.0 \mathrm{pg} / \mathrm{mL}$ ).

\section{Discussion}

Patient 1 exhibited stupor, negativism, tachycardia, and autonomic instability that manifested as labile blood pressure, diaphoresis, and fever $\left(>38^{\circ} \mathrm{C}\right)$, but did not display muscle rigidity. Patient 2 exhibited intermittent excitement and stupor, negativism, tachycardia, labile blood pressure, diaphoresis, and hyperthermia $\left(>38^{\circ} \mathrm{C}\right)$, and similarly did not display muscle rigidity. Häfner and Kasper ${ }^{6}$ proposed the diagnostic criteria for malignant catatonia, which consist of the following manifestations: acute and severe catatonia with stupor or excitement, hyperthermia $\left(\geq 38.0^{\circ} \mathrm{C}\right)$, tachycardia $(>120$ beats per minute), or hypertension $(>150 / 100 \mathrm{mmHg})$, and increased muscle tone. These diagnostic criteria cannot reliably differentiate malignant catatonia from neuroleptic malignant syndrome. However, catatonic symptoms including stupor and excitement are prominent features of malignant catatonia, and both patients presented in this report exhibited stupor or excitement. Muscle rigidity occurs in both malignant catatonia and neuroleptic malignant syndrome, but it is either absent or mild in malignant catatonia whereas it presents as "lead pipe" rigidity in neuroleptic malignant syndrome. ${ }^{2}$ Thus, the absence of muscle rigidity in our patients is more consistent with a diagnosis of malignant catatonia. Next, patient 1 was not given neuroleptics, but patient 2 was given neuroleptics. As for the relationship between malignant catatonia and neuroleptics, when Stauder introduced the term "lethal catatonia" in 1934, neuroleptics had not been found. Therefore, strictly speaking, when a patient shows clinical symptoms pathognomonic for malignant catatonia without neuroleptics being administered and other physical diseases are ruled out, malignant catatonia is diagnosed. However, in recent years, nearly all psychiatric patients are given neuroleptics. In fact, patients reported recently with malignant catatonia were given neuroleptics. Finally, high catecholamine levels were found in the urine or plasma of these two patients. The excessive catecholamine excretion suggests the existence of pheochromocytoma or a related disease. ${ }^{7}$ However, a computed tomography scan of the abdomen was negative for pheochromocytoma in patient 1 and although a detailed investigation was not performed in patient 2 , the episode suggestive of pheochromocytoma did not recur thereafter. Therefore, these two patients were diagnosed with malignant catatonia.

It has been reported that levels of catecholamines obtained from plasma or 24-hour urine samples increase during strenuous exercise. ${ }^{8-10}$ Therefore, the possibility that increased catecholamine levels are a consequence of this excitement should be considered given that a primary symptom of malignant catatonia is severe excitement. However, the fact that patient 1 exhibited only motor immobility manifested as stupor during the disease course is at odds with this interpretation. Moreover, blood was withdrawn for catecholamine sampling from patient 2 before he showed intermittent excitement. Considering the above-mentioned points, the excessive catecholamine levels observed in these patients are more likely to be related to the clinical symptoms of malignant catatonia than to be an artifact of activity level. In addition, both patients presented with symptoms of autonomic instability (including tachycardia, labile blood pressure, and diaphoresis) at the time that their catecholamine levels were measured. Thus, it seems likely that increased urine or plasma catecholamine levels reflect hyperactivity of the peripheral sympathetic nervous system in malignant catatonia.

Relatively few studies have investigated the pathophysiology of malignant catatonia. Gjessing ${ }^{11}$ found a remarkable increase in urinary catecholamines during the active phase (stupor) of periodic catatonia. Specifically regarding malignant catatonia, Rummans and Bassingthwaighte ${ }^{12}$ reported high urinary adrenaline and noradrenaline values in a case of malignant catatonia, and Philbrick and Rummans ${ }^{1}$ identified a case showing increased levels of urinary vanillylmandelic acid. Our laboratory previously found high urinary adrenaline, noradrenaline, and vanillylmandelic acid values in a single case of malignant catatonia. ${ }^{13}$ Importantly, the findings of the present study are consistent with those of the previous one in supporting the association between malignant catatonia and high catecholamine levels.

As previously described in this report, the clinical symptoms of malignant catatonia are somewhat different from those of neuroleptic malignant syndrome. Nevertheless, some investigators insist that the two disorders share a common pathophysiology. ${ }^{1,14}$ Specifically, it has been postulated that an abnormality of dopaminergic neurotransmission may underlie both neuroleptic malignant syndrome ${ }^{15}$ and malignant catatonia. ${ }^{4,5}$ Northoff et $\mathrm{al}^{16}$ reported that levels of the dopamine metabolite, plasma homovanillic acid, in 37 catatonic (not malignant catatonia) patients were significantly higher than in control subjects. In the 
present study, levels of plasma homovanillic acid were not measured; therefore, a direct comparison cannot be made between these two cases and the study reported by Northoff et al. Nevertheless, the finding of an increased dopamine level in patient 2 with malignant catatonia is consistent with these earlier results. The findings in the present study cannot entirely explain the pathophysiology of malignant catatonia, but do indicate that hyperactivity of the sympathetic nervous system may be an important factor. Further, it is interesting to consider that previous studies have reported increased urine and plasma catecholamine levels in neuroleptic malignant syndrome. ${ }^{17,18}$ Although the data are insufficient to conclude that neuroleptic malignant syndrome and malignant catatonia are variants of the same disorder, these two disorders may be highly similar in terms of sympathetic nervous system hyperactivity.

This report is limited by the small number of cases studied. Further investigations involving a larger series of malignant catatonia cases are warranted, and it will be necessary to determine whether the excessive catecholamine excretion observed in these cases is a specific finding in malignant catatonia or is also present in other types of catatonia.

\section{Disclosure}

The author reports no conflicts of interest in this work.

\section{References}

1. Philbrick KL, Rummans TA. Malignant catatonia. J Neuropsychiatry Clin Neurosci. 1994;6(1):1-13.

2. Singerman B, Raheja R. Malignant catatonia - a continuing reality. Ann Clin Psychiatry. 1994;6(4):259-266.
3. Taylor MA, Fink M. Catatonia in psychiatric classification: a home of its own. Am J Psychiatry. 2003;160(7):1233-1241.

4. Carroll BT, Taylor RE. The nondichotomy between lethal catatonia and neuroleptic malignant syndrome. J Clin Psychopharmacol. 1997;17(3): 235-236.

5. Fink M, Taylor MA. The catatonia syndrome. Arch Gen Psychiatry. 2009;66(11):1173-1177.

6. Häfner H, Kasper S. Acute life-threatening catatonia. Nervenarzt. 1982;53(7):385-394. German.

7. Korevaar TIM, Grossman AB. Pheochromocytomas and paragangliomas: assessment of malignant potential. Endocrine. 2011; 40(3):354-365.

8. Lehmann M, Keul J. Age-associated changes of exercise-induced plasma catecholamine response. Eur J Appl Physiol. 1986;55(3):302-306.

9. French DN, Kraemer WJ, Volek JS, et al. Anticipatory responses of catecholamines on muscle force production. J Appl Physiol. 2007; 102(1):94-102.

10. Rogers PJ, Tyce GM, Weinshilboum RM, O'Connor DT, Bailey KR, Bove AA. Catecholamine metabolic pathways and exercise training. Circulation. 1991;84(6):2346-2356.

11. Gjessing LR. A review of periodic catatonia. Biol Psychiatry. 1974;8(1):23-45.

12. Rummans TA, Bassingthwaighte ME. Severe medical and neurologic complications associated with near-lethal catatonia treated with electroconvulsive therapy. Convuls Ther. 1991;7(2):121-124.

13. Nisijima K. Malignant catatonia accompanied by high urinary catecholamine levels mimicking the presentation of pheochromocytoma. Psychiatry Clin Neurosci. 2009;63(3):428-429.

14. Fink M. Neuroleptic malignant syndrome and catatonia: one entity or two? Biol Psychiatry. 1996;39(1):1-4.

15. Strawn JR, Keck PE, Caroff SN. Neuroleptic malignant syndrome. Am J Psychiatry. 2007;164(6):870-876.

16. Northoff G, Demisch L, Wenke J, Pflug B. Plasma homovanillic acid concentrations in catatonia. Biol Psychiatry. 1996;39(6):436-443.

17. Feibel JH, Schiffer RB. Sympathoadrenomedullary hyperactivity in the neuroleptic malignant syndrome: a case report. Am J Psychiatry. 1981;138(8):1115-1116.

18. Gurrera RJ, Romero JA. Sympathoadrenomedullary activity in the neuroleptic malignant syndrome. Biol Psychiatry. 1992;32(4): 334-343.
Neuropsychiatric Disease and Treatment

\section{Publish your work in this journal}

Neuropsychiatric Disease and Treatment is an international, peerreviewed journal of clinical therapeutics and pharmacology focusing on concise rapid reporting of clinical or pre-clinical studies on a range of neuropsychiatric and neurological disorders. This journal is indexed on PubMed Central, the 'PsycINFO' database and CAS.

\section{Dovepress}

The manuscript management system is completely online and includes a very quick and fair peer-review system, which is all easy to use. Visit http://www.dovepress.com/testimonials.php to read real quotes from published authors. 